\title{
REHABILITATION OF PATIENT WITH MAXILLECTOMY USING DEFINITIVE HOLLOW BULB OBTURATOR
}

\section{DR. PRIYANKA TIWARI}

Department of Prosthodontics \& Crown and Bridge, K.M. Shah Dental College, Sumandeep Vidyapeeth University, Gujarat, India

ABSTRACT
The defects of the maxilla are fabricated by palatal clefts or resection of tumours or malignancies in the orofacialsection
and are treated by surgical methods. Surgical techniques develop defects creatingoro-nasal communication and patients
develop problems in speech,deglutition, mastication and appearance. To overcome these problems obturators are
fabricated with light weight to enhanceretention and stability of the prosthesis.Hence,the best treatment modality in
maxillectomy patients is hollow bulb maxillary obturator prosthesis.A partial or total maxillectomy can be most benefited
by this treatment. This article is a description of a clinical case that was treated successfully by using a closed hollow bulb
(definitive) obturator.
KEYWORDS: Definitive Hollow Bulb Obturator, Closed Hollow Bulb, Single Piece Obturator, Maxillary Defect, Hemi
Maxillectomy, Maxillofacial Prosthesis

Received: Sep 22, 2020; Accepted: Oct 12, 2020; Published: Nov 05, 2020; Paper Id.: IJDRDDEC20202

\section{INTRODUCTION}

Malignant tumours of the upper gum and hard palate account for 1-5\% of malignant neoplasms of the oral cavity; two thirds of the lesions which involve these areas are squamous cell carcinomas. ${ }^{1}$ Once the carcinoma invades the underlying bone, they may be detected.Ablative surgery is used to control malignancies and other abnormal growth in the oral cavity. ${ }^{2}$ The effects of postsurgical maxillary defect are fluid leakage through the nose and hypernasal speech. The best treatment options available are alveolectomy, palatectomy, maxillectomy, which may be total or partial.Defects are developed by surgical treatment of benign and malignant neoplasms, trauma, or congenital defectswhich creates problems in aesthetics, speech and mastication. Hence the objective should be to restore mastication, deglutition, speech, achieve normal orofacial appearance and to rehabilitate maxillary defect involving multidisciplinary method.In large defects, obturatorvertically covers the defect and horizontally covers the undercuts at the cost of its size \& weight. Prosthetic rehabilitation with an obturator allows restores theaesthetics and deglutition, speech and mastication. Hollowbulb obturator reduces the weight of the prosthesis and makes it lighter thereby reducing the pull of gravity. This case report displays the creation of one piece closed hollow bulb definitive obturator for a patient with acquired maxillary defect (Aramany's Class.1) on the right side (unilateral); with the teeth on left side were left intact.

\section{CASE REPORT}

64 Yrs. old male was referred to the department of Prosthodontics. The patient complained of inability in chewing, swallowing, speaking, deformity of upper midface and hole in the palate. The patient wanted to cover the hole 
present in the palate and get replacements of missing upper \& lower teeth. Intraoral examination showed missing 31,32 and $11,12,13,14,15,16,17$ and partial maxillectomy. Extraoral examination showed depressed cheek, nasolabial fold and lack of lip support on the right side. There was no significant medical history of the patient. However, the patient had squamous cell carcinoma on the left maxilla for which hemimaxillectomy of the same side was performedone year ago. Diagnosis was Armany's Class. 1 extending till the floor of the orbit. Treatment plan was to fabricate closed hollow bulb definitive obturator and conventional removable partial denture with 31,32 .

\section{A) PROCEDURES:}

- Intraoral examination was performed. Using a gauge defect was blocked out and then primary impressions were made with Alginate using perforated stock tray. After removable of the impression, wax was placed on the gauge to properly cover the defect. A diagnostic cast was made, consisting of the wax covered on the defect. (Figure.1 and 2)

- Custom tray was fabricated with five diamond spaced stops. (Figure.3)

- Border moulding was performed and impression of the defect was registered using putty. Wash impression was made using light body polyvinylsiloxane. Then master cast was made. (Figure. 4 and 5)

- Jaw relation was recorded and Try-in was done with monoplane dentition taking into account the aesthetics and phonetic requirements. (Figure. 6 and 7)

- Surveying of the master cast was done to eliminate all the undercuts \& for clasp placement and bracing was done on the cast by clasp. (Figure. 8 and 9)

- Flasking was done in the conventional manner. (Figure. 10)

- A hollow bulb was made with autopolymerising acrylic resin. Autopolymerising acrylic resin was covered onto the defect area, which was filled with ice and then a lid of autopolymerising acrylic resin was made. (Figure. 11, 12, $13,14)$

- After dewaxing was done with the bulb placed in the defect. (Figure. 15)

- After complete polymersization, a round bur was used to make a hole and the water was removed. To check hollow bulb, the bulb was made to floating in the water. The hollow cavity was air dried and then opening was sealed with autopolymerising acrylic resin after removing of the ice. (Figure. 16, 17)

- After acrylization of the obturator was retrieved in the usual manner. Hollow bulb obturator was ready with Removable partial denture with 31, 32. (Figure. 18)

- Obturator and RPD was finished, polished and delivered to the patient's mouth and all the required adjustments were performed. (Figure. 19)

- Check-upswere done at 24 hours, one week, one month and three-month intervals to follow the post insertion protocol.

\section{B) IMAGES:}

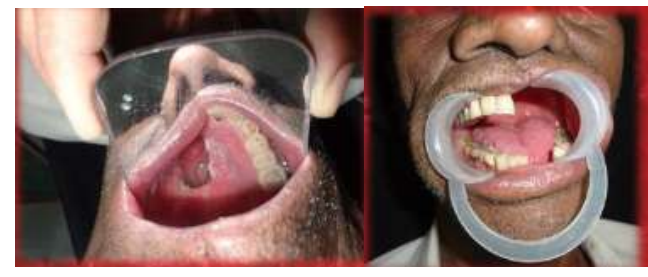

Figure 1: Intraoral pictures 


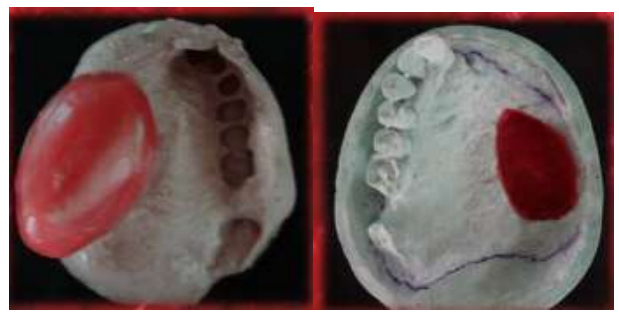

Figure 2: Primary impression \& primary cast with defect covered by wax

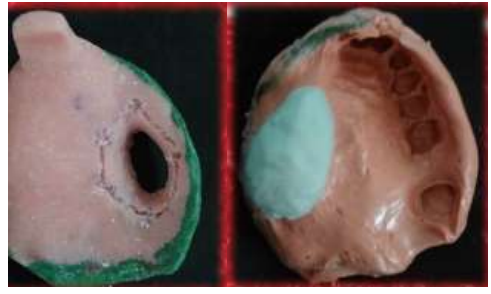

Figure 3: Special tray with five diamond shaped stops \& Figure 4: Light body impression and defect covered with putty

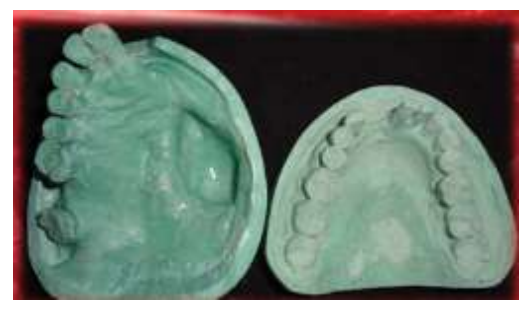

Figure 5: Master Cast

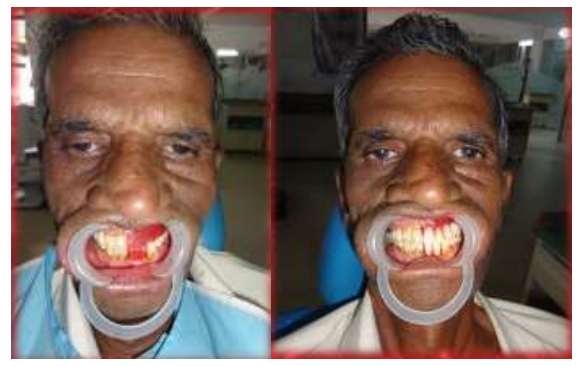

Figure 6 \& Figure.7: Jaw relation \& Try In

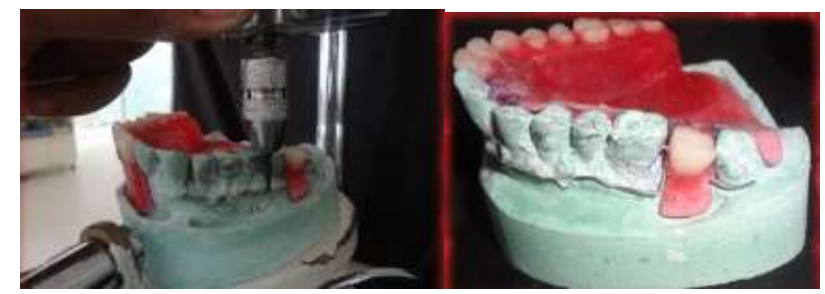

Figure 8 \& Figure 9: Surveying done and Bracing done on cast by clasp

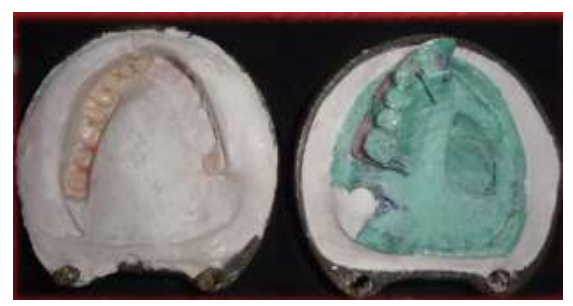

Figure 10: Flasking done 


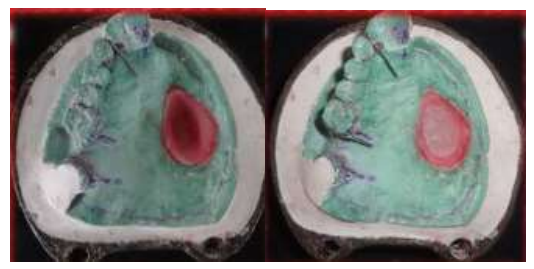

Figure $11 \&$ Figure.12: Base of the bulb fabricated by acrylic with wax spacer \& Ice incorporated in the bulb

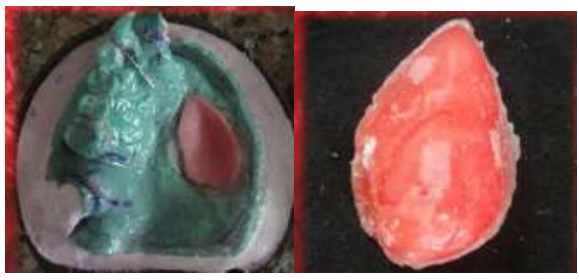

Figure 13 \& Figure. 14: Lid of the bulb fabricated by acrylic \& Bulb fabricated

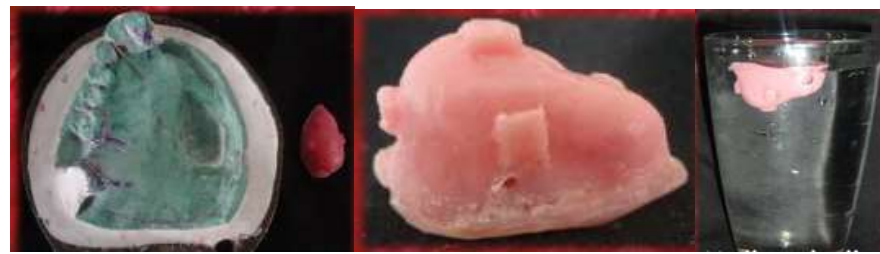

Figure 15 \& Figure 16: Dewaxing done \& Hole made in the bulb and the water was removed and Figure. 17-Hollow bulb floating in the water

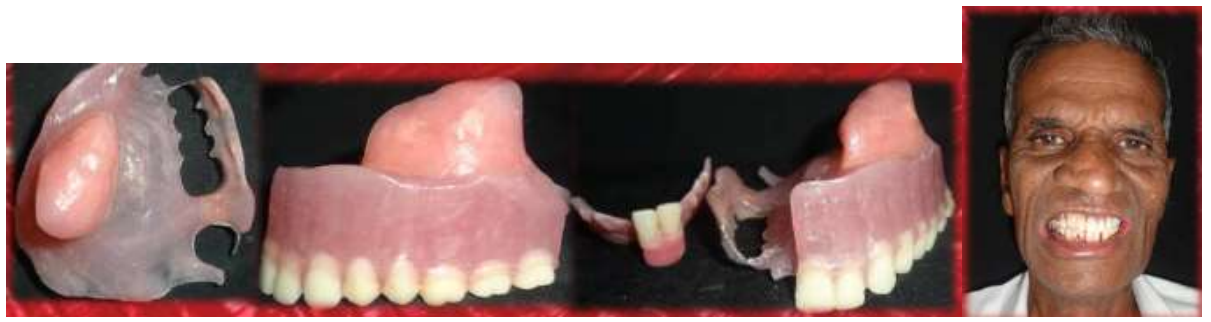

Figure 18: Hollow bulb obturator with RPD with 31, 32\& Figure. 19- Obturator and RPD placed in patient's mouth

\section{DISCUSSIONS}

Obturators are used for treatment of acquired maxillary defect.Many advantages are present with the hollow bulb obturator, they are as follows due to the light denture automatically the weight of the prosthesis is less hence it helps in retention, improved mastication and deglutition, also transmits less pressure to the surrounding tissues so further helping in the rebuilding of the tissues, low chances of physiologic changes in the muscle balance and patient comfort. ${ }^{3}$ Closed obturator fabrication helps in remaining hygienic, has less maintenance, decreases air space \& fluid collection in the defect of the maxilla, hence increasing the support, stability and retention. ${ }^{5}$ Definitive obturator restores the function of mastication speech and aesthetics and also serves as barrier between the oral and nasal cavity. ${ }^{6}$ Care should be taken during the fabrication to check the site for fresh complications, and only when the size of the defect is dimensionally stable. This type of obturator should be given 3-6 months after surgery. ${ }^{7}$ Clarity of sound can be improved by using bulb extension as the resonance improves. ${ }^{3}$ Solid bulb can cause many problems such as increased weight, resulting in reducing the patient comfort and retention, stability \& support. 7 to $33 \%$ weight can be reduced according to $\mathrm{Wu}$ and Schaaf. ${ }^{4} 24 \%$ weight reduction of the obturator helps in improving retention, stability and support. ${ }^{3}$ There are many materials which can be used to make hollow bulb obturator. ${ }^{8}$ One method is to design the two halves of the obturator separately and joining them by an auto polymerizing resin. ${ }^{11}$ Sugar and Ice can be used in the defect portion and then removed after processing by making small holes, according 
to Parel et al. ${ }^{9}$ Double flask technique for making hollow bulb obturator was also used by El Mahdy et al. ${ }^{10}$ Disadvantage of this technique was bulb and dentulous area was processed separately hence creating extra steps. Another modification of this technique requiring multiple flasks was demonstrated by McAndrewet al known as investment method for closed bulb obturator. ${ }^{12}$ Bulb portion can be made separately or together with oral portion and joined by either light cure resin or auto polymerizing acrylic resin. Designing of the obturator as single piece or two pieces is supported by literature. ${ }^{4}$ Single piece obturator has many benefits such as being easy to clean and smooth finish of the final prosthesis. In this case, bulb portion is made first which was used as a reservoir for ice and then joined with oral portion using heat cure acrylic resin. Heat cure acrylic resin prosthesis has many benefits which are increases the life of the prosthesis, reduces leakages and minimizes the stain. The purpose of using ice in the initial stage was to maintain the uniform space in the bulb. ${ }^{4}$ Also one another benefit was that same flask of the base fabrication was used again to make other part of the obturator. After this, by creating holes, the water can be flushed out and then sealed by autopolymerizing resin. Many studies have suggested using of sugar and ice during processing, which was later withdrawn by making holes. ${ }^{8,13,14}$

\section{CONCLUSIONS}

Maxillary defects caused by hemimaxillectomy can be very well rehabilitated by the use of removable partial denture and hollow obturator. ${ }^{6}$ Speech and swallowing are restored, and mastication is accomplished with the residual maxillary dentition. In patients with maxillary defects, surgical procedures cannot provide satisfactory cosmetic and functional rehabilitation. The obturator bulb covered the under-cuts on the defect side and separated the oral cavity from sino-nasal cavities to restore the function and structure. ${ }^{15}$ It also supported the facial tissues and provided more comfort and stability without compromising retention. To achieve complete patient satisfaction, informing and instructing patients about obturator use, routine psychological care, and institution of speech therapy should be done.

\section{REFERENCES}

1. Ashish. R. Jain, Jacob M. Philip, R. Pradeep et al. "Cast Retainer Hollow Bulb Obturator for a Maxillary Defect-A Case Report Ashish". International Journal of Dental Sciences and Research2014; 2(6): 164-167.

2. Ruksana Farooqui et al. "A simple and innovative technique of fabrication of a definitive closed hollow bulb obturator". International Journal of Current Research2019; 11(12): 8711-8713.

3. RAJALAXMI, V., et al. "EFFECTIVENESS OF CONSTRAINT INDUCED MOVEMENT THERAPY IN COMPARISION WITH TRADITIONAL REHABILITATION THERAPY IN TREATING UPPER EXTREMITY OF THE ACUTE AND SUBACUTE STROKE PATIENTS." (2008). TJPRC: International Journal of Physiotherapy \& Occupational Therapy (TJPRC: IJPOT) 2. 2, Dec 2016, 17-24

4. Dr. Jay Mehta, Dr. Raghavendra Swamy, Dr. Dhakshaini et al. "Closed hollow bulb obturator with replicated palatal rugae in a hemimaxillectomy patient-a clinical report”. Int. J. Adv. Res; 5(4): 1096-1103.

5. David Charles P, Anusha Rajendran, Vidyashree Nandini et al. "Techniques for fabrication of interim closed hollow bulb obturator in a patient with Class II Armany's defect". Karnataka Prosthodontic Journal2017; 1(3):6-12.

6. PARRE, MEENAKSHI DEVI, and B. SUJATHA. "ADAPTIVE ROBOTIC NEURO-REHABILITATION HAPTIC DEVICE FOR MOTOR AND SENSORY DYSFUNCTION PATIENTS." International Journal of Mechanical and Production Engineering Research and Development (IJMPERD) 9. 6, Dec 2019, 131-138

7. Suwal P, Shrestha P. "Hollow bulb obturator in right total maxillectomy patient". Bangladesh Journal of Medical Science2015; 14(1): 91-94. 
8. Preeti Chaubey, Rahul Tripathi, Ajay Singh. "Rehabilitation of hemi-maxillectomy with a definite one piece hollow bulb obturator”. J Maxillofac Surg 2018;9:82-5.

9. Chauhan, M. A. N. D. A., R. A. J. N. I. Kalra, and D. H. A. R. M. E. N. D. R. A. Kumar. "Benign paroxysmal positional vertigo in rehabilitation setting: review of diagnosis and intervention." International Journal of Medicine and Pharmaceutical Science 6.1 (2016): 67-78.

10. Madhumathi V, Parvathi Devi MK. “Rehabilitation of a partially dentate patient with closed hollow bulb obturator: A case report”. Journal of Indian Academy of Dental Specialist Researchers 2014;1(1):31-34.

11. Parthasarathy Natarajan, C. Ramasamy, T.V. Padmanabhan. "Rehabilitation of a partial maxillectomy patient with silicone relined hollow bulb obturator". Journal of Dental and Medical Sciences 2013; 11(3): 01-05.

12. ANANDH, S., R. RAJA, and J. JAYA PRAKASH. "EFFICACY OF SEATED BALANCE EXERCISES WITH SENSORY FEEDBACK ON BALANCED SITTING AMONG HEMORRHAGIC STROKE PATIENTS." TJPRC: International Journal of Physiotherapy \& Occupational Therapy (TJPRC: IJPOT) 3.2, Dec 2017, 1-8

13. Parel SM, LaFuente H. Single-visit hollow obturators for edentulous patients. J Prosthet Dent.1978; 40:426-429.

14. El Mahdy AS: Processing a hollow obturator. J Prosthet Dent 1969; 22:682-686.

15. Mahinder Dubasi, Sujesh Macha, Ravikumar Chitturi et al. "Prosthetic management of hemi maxillectomy defect with hollow bulb obturator- a case report”. Indian Journal of Applied Research 2007;7(6): 79-96.

16. McAndrew KS, Rothenberger S, Minsley GE: An innovative investment method for the fabrication of closed hollow obturator prosthesis. J Prosthet Dent 1998; 80:129-132.

17. Ruchi Jain, Kamal Shigli, Rajeev Srivastava et al. "Hollow bulb obturator for congenital velopharyngeal insufficiency". J InterdiscipDentistry 2016;6:75-9.

18. Harshita Alva, Krishna Prasad D, Anupama Prasad D. "Prosthodontic Rehabilitation of a patient with hollow bulb obturator: a case report”. NUJHS 2012;2(2):60-62.

19. Kanchan P. Dholam, Karthik M, Sadashiva et al. "Rehabilitation of large maxillary defect with two-piece maxillary obturators". J Can Res Ther 2015;11:664. 